\title{
RAIONISMO: LUZ NA TELA, SOMBRA NA LITERATURA
}

Farlley Derze ${ }^{1}$

farlley@unb.br

Resumo: Este estudo é sobre a representação da luz na pintura ocidental. Tem seu foco na pintura de um movimento russo, do século XX, denominado Raionismo. Por ser classificado na literatura como arte não-figurativa, buscou-se identificar se seria a primeira expressão pictórica nãofigurativa na Rússia. Descobrir como a literatura aborda o Raionismo foi objetivo desse estudo. A metodologia foi a pesquisa bibliográfica e iconográfica, com base em literatura traduzida para o português e publicada no Brasil, e livros editados em francês. Trinta livros foram pesquisados e apenas dez trataram do Raionismo. Concluiu-se que o Raionismo foi o primeiro movimento russo a apresentar uma pintura não-figurativa, sem a tradição de uma narrativa.

Palavras-chave: Representação da luz, Pintura moderna, Raionismo.

Abstract: This study is about the representation of the light in the painting occidental person. It has its focus in the painting of a Russian movement, of century XX, called Rayonism. For being classified in literature as not-figurative art, one searched to identify if it would be the first notfigurative pictorial expression in Russian. To discover as literature approaches the Rayonism was objective of this study. The methodology was the bibliographical and iconographic research, on the basis of literature translated into the portuguese and published in Brazil, and books edited into the french. Thirty books had been searched and only ten had dealt with the Rayonism. It was concluded that the Rayonism was the first Russian movement to present a not-figurative painting, without the tradition of a narrative.

Key-words: Representation of the light, Modern painting, Rayonism.

\section{INTRODUÇÃO}

Este estudo insere-se no campo da estética e tomou por base uma amostra da literatura sobre História da Arte Moderna publicada no Brasil, e uma amostra editada em francês. Determinados livros sobre a Arte Ocidental findam por ser uma fonte visual abundante da pintura européia. Neles é possível verificar que desde o período medieval aos dias atuais muitas representações produzidas nos mais diversos suportes (iluminuras, pinturas, afrescos, têmperas) incluem a luz representada pictoricamente.

${ }^{1}$ Farlley Derze é doutorando em Arquitetura e Urbanismo pela FAU-UnB. REVISTA DE ESTÉTICA E SEMIOTICA, BRASÍLIA, V. 1, N. 1 P. 91 -101, JUL./DEZ. 2011 


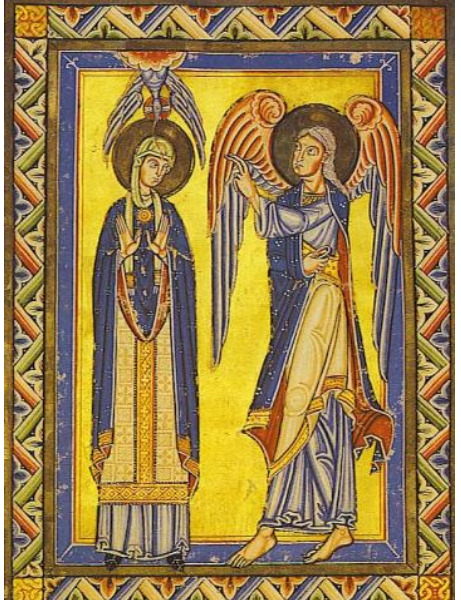

A anunciação (1150)

De um evangelho manuscrito suábio Fonte: GOMBRICH, 1999, p. 180

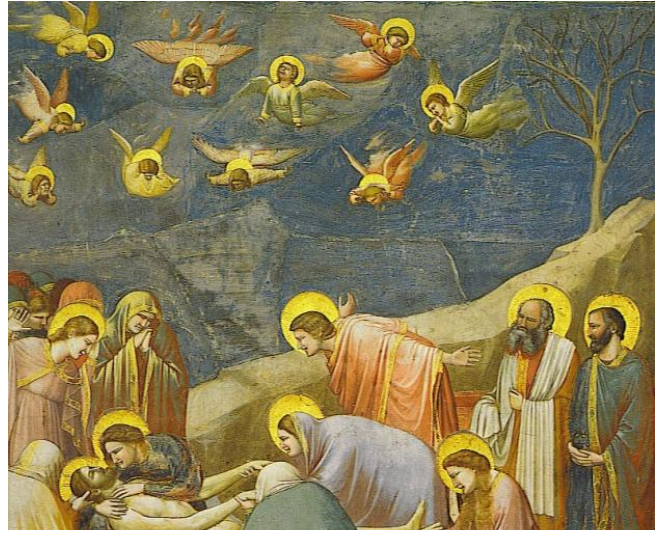

A lamentação de Criso (1305)

Afresco de Giotto, na Capela dellÁrena - Pádua

Fonte: GOMBRICH, 1999, p. 203

Nas obras acima, o halo ao redor das cabeças representa um "ser iluminado", conforme a filosofia de Santo Agostinho em sua obra "Confissões", ao se referir às divindades da mitologia cristã. Na obra do italiano Giotto as divindades também têm um halo, mas há pessoas sem o halo, que seriam os seres do mundo secular ou seres sem "valor" divino. Mais quatro exemplos sobre a luz representada na pintura, seguem-se nas obras abaixo.

A pintora portuguesa Josefa de Óbidos (1630-1684) representa a luz artificial provinda de um candeeiro de ferro a óleo. O pintor espanhol Goya (1746-1828) representa a luz artificial e uma luminária contendo em seu interior, possivelmente, a julgar pela época, uma vela feita de espermacete (óleo de baleia). Cabe ressaltar que a luz elétrica ainda não havia sido inventada, bem como não se encontrava disponível a parafina para confecção de velas.

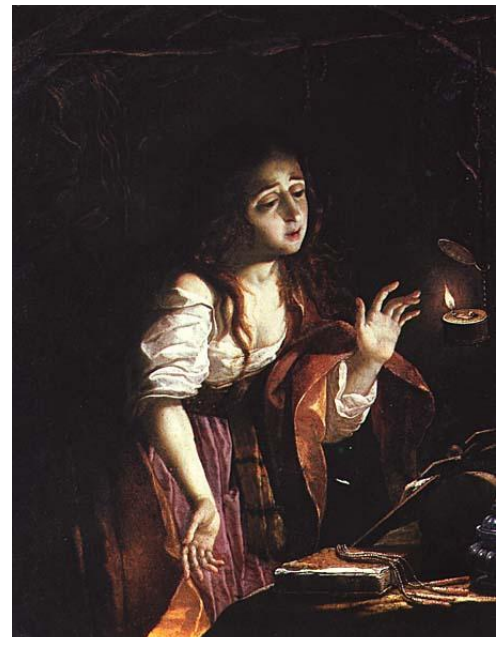

Santa Maria Madalena (1650) Josefa de Óbidos

Fonte: KEMP, 2006 p. 202

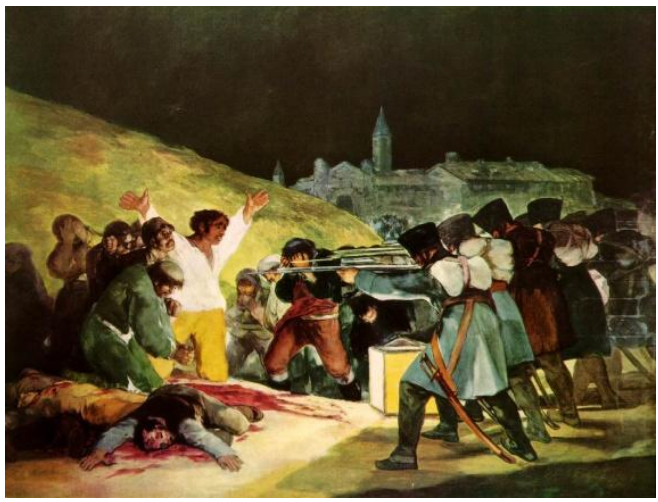

Execução de 3 de maio de 1808 (1814) Francisco Goya Fonte: KEMP, 2006 p. 314 
$\mathrm{Na}$ obra do pintor americano Frederick Edwin Church (1826-1900), que se dedicava a pintar paisagens, ele representa a luz natural (luz do sol), e utiliza uma palheta de cores predominantemente quentes, típicas no ambiente natural de um entardecer.

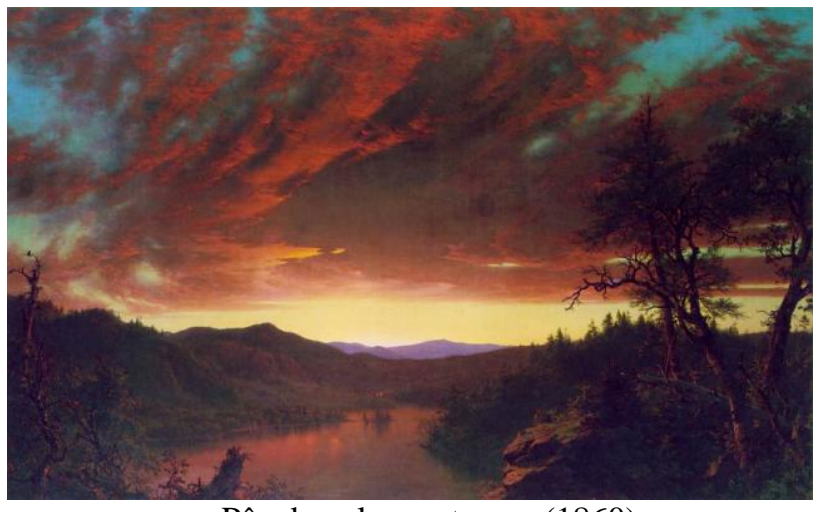

Pôr-do-sol na natureza (1860)

Frederick Edwin Church

Fonte: KEMP, 2006 p. 329

Na obra do pintor francês Gustave Caillebotte (1848-1893) em que a luz natural encontrase difusa, típica de um dia nublado, representada em sua translucidez branca, percebe-se no segundo plano um poste da iluminação pública, ainda a gás, pois a iluminação pública elétrica era inexistente no ano em que o quadro foi pintado (1877).

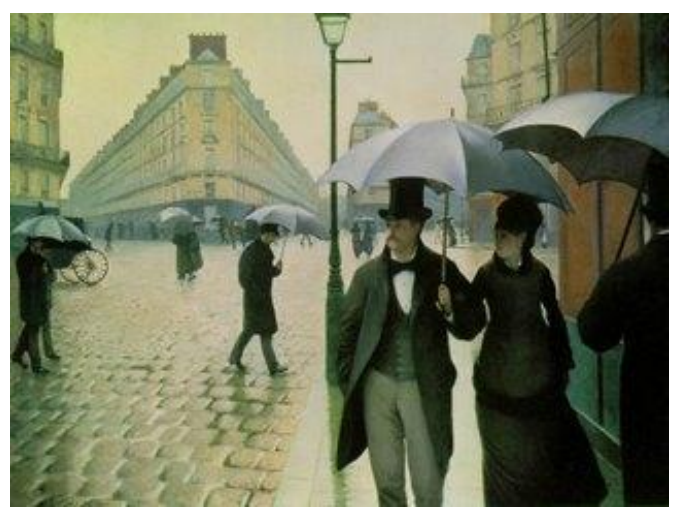

Paris, tempo de chuva (1877)

Gustave Caillebotte

Fonte: KEMP, 2006 p. 331

Os exemplos supramencionados compõem uma ínfima amostra da pintura figurativa, que predominou das iluminuras e afrescos medievais até o séc. XIX na Europa, onde a luz foi representada ora simbolicamente em atendimento aos cânones religiosos cristãos, ora em correspondência à sua aparência cotidiana, tanto a luz natural como a luz artificial. Entretanto, ao 
raiar o séc. XX, pela primeira vez na história dessa pintura ocidental, um russo chamado Larionov representou a luz na forma de seus raios, que deu origem ao nome "raionismo" para tal estética pictórica. O raionismo não pintaria pessoas, não pintaria paisagens, não pintaria objetos, mas apenas "os raios refletidos no espaço" - os raios de luz - raionismo.

O interesse desse estudo por este movimento reside nas afirmações do próprio criador do movimento, Mikhail Larionov, que diz: "Se quisermos pintar literalmente aquilo que vemos, então precisamos pintar a totalidade dos raios que o objeto reflete" (DEMPSEY, 2003, p. 102).

Sob esse ponto de vista, busquei identificar se o raionismo seria a primeira expressão pictórica não-figurativa, na Rússia e, ainda, como a literatura abordou o movimento em obras editadas e publicadas no Brasil, e obras da literatura francesa. Cabe elucidar que preferi não abordar como objeto de estudo, a pintura dos impressionistas e pontilhistas, que embora tenham se dedicado às questões referentes à luz ou luminosidade ambiente, não deram nenhum título aos seus movimentos (estilos), a partir do vocábulo luz ou raios de luz. Os russos o fizeram.

\section{O AMBIENTE DA SEGUNDA METADE DO SÉCULO XIX}

A sociedade européia, da qual fazia parte os artistas da pintura, literatura, música, dança, teatro, dentre os cidadãos, experimentavam um frescor intelectual de mudança no ritmo social urbano, com a invenção da máquina fotográfica, do moderno meio de comunicação (o telégrafo), os modernos meios de transporte movidos a vapor, a chegada da iluminação elétrica, e logo depois, do cinema. Não eram apenas revoluções de máquinas, mas também revoluções na vida mental das pessoas. Gustave Flaubert, com sua obra literária "Madamme Bovary" (1857), tida como precursora do Realismo europeu, e no raiar do século XX, Freud e Einstein, participavam de uma profusão de idéias que tornou sentimentos, ciência e tecnologia solúveis numa mesma atmosfera de independência e buscas por novas formas de percepção do homem e seu meio. Um século moderno, dinâmico, veloz, elétrico e, sobretudo, relativo.

Um tal horizonte de possibilidades fez-se favorável e encorajador para que muitos artistas europeus acreditassem em sua própria independência de estilo, malgrado os valores estéticos ainda em voga e sob o juízo do ambiente acadêmico da L'École des Beaux Arts. Mas era uma questão de tempo para que uma marcha de artistas independentes e dissidentes acadêmicos provocasse a REVISTA DE ESTÉTICA E SEMIOTICA, BRASÍLIA, V. 1, N. 1 P. 91 -101, JUL./DEZ. 2011 
dissolução da substância narrativa na pintura, entendida por Baxandall (2006, p. 118) como um "padrão de intenção". A narrativa sofreria um golpe mais agudo pelas obras das vanguardas russas e do cubismo. Tais obras da pintura comprometeriam o padrão de percepção do espaço tridimensional, então representado na tela bidimensional, cujo aperfeiçoamento se deu no Renascimento e atravessou os séculos até sua fragmentação figurativa pela pintura moderna.

Os pintores modernos da primeira metade do séc. XX ofereceram aos seus "clientes", um novo cardápio formal: linhas, círculos, sinuosismos e geometrismos, cores multifacetadas, espaços redimensionados, perspectiva chacoalhada, onde o conteúdo figurativo ou temático torna-se fragmentado por superposições, deslocamentos e rearranjos das partes constituintes do todo. Eram obras impregnadas de um sabor geométrico, em convivência com os ruídos da produção industrial galopante na Europa, e sua profusão de materiais, como vidro e metais, redesenhados e multiplicados para funcionar na vida urbana, arquitetônica e doméstica.

Um novo mundo composto de grandes multidões excitadas pelo trabalho, de marés polifônicas de revolução nas capitais modernas, do vibrante fervor noturno dos arsenais e dos estaleiros que brilham com violentas luas elétricas. (PERLOFF, 1993, p. 165).

\section{O RAIONISMO: 1912 A 1914.}

O meu interesse pelo Raionismo advém de meu interesse na pesquisa sobre a representação da luz na pintura ocidental. O Raionismo surge na Rússia de 1912 a 1914, como uma das vanguardas russas que se encaixavam no cardápio de movimentos modernistas, cujos "chefes de cozinha" (franceses, italianos e russos), experimentavam à sua maneira, novos temperos de cores, linhas e jogos de perspectiva espacial, para servir aos olhos do público da primeira metade do século XX, seus experimentos para uma culinária pictórica modernista. A "receita pronta" que o academicismo vinha fornecendo já não seria suficiente para o paladar visual das novas gerações.

O Raionismo assumiu a luz como protagonista, isto é, como “objeto" a ser representado, em si - a personagem principal. As intenções declaradas pelo russo Larionov, criador do raionismo, no que se refere ao produto pictórico que caracterizaria seu movimento artístico, eram a de que as pinturas raionistas não revelassem preocupações com a representação de objetos, mas sim, dos raios refletidos a partir deles. "Larionov visa à construção de um espaço sem objetos, REVISTA DE ESTÉTICA E SEMIOTICA, BRASÍLIA, V. 1, N. 1 P. 91 -101, JUL./DEZ. 2011 
absoluto, constituído apenas por movimento e luz - ritmo dinâmico de raios entrecruzados que se decompõem nas cores do prisma" (ARGAN, 1992, p. 324).

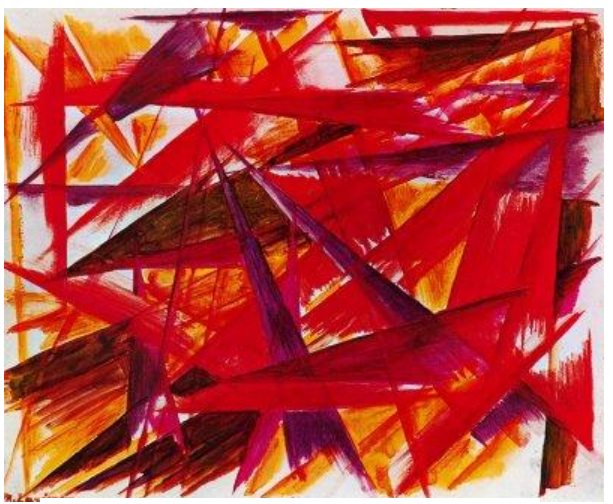

Raionismo vermelho (1913)

Mikhail Larionov

Fonte: Internet.

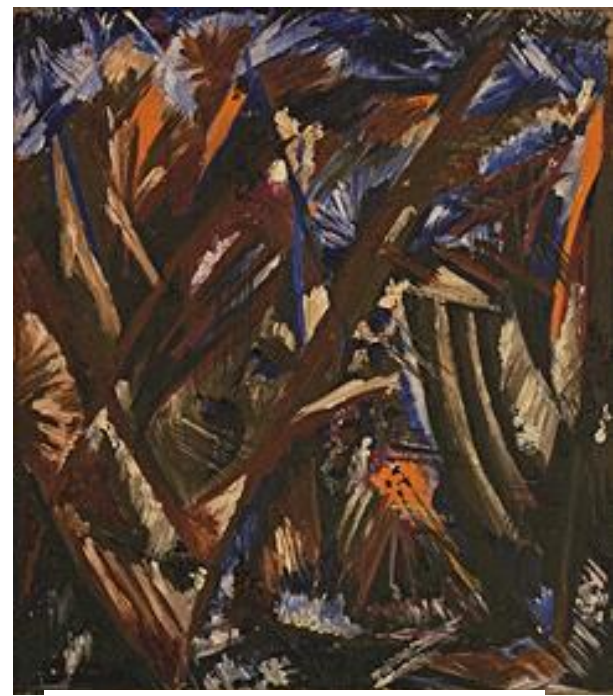

Landscape (1912)

Natalia Gontcharova Fonte: Internet.

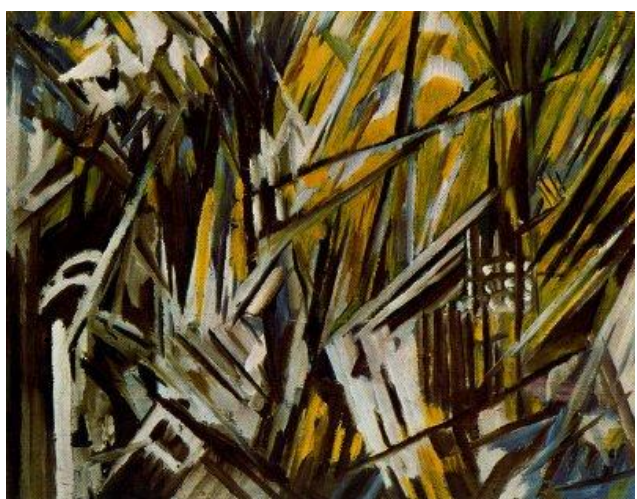

Raionismo moreno e amarelo (1912)

Mikhail Larionov

Fonte: Internet.

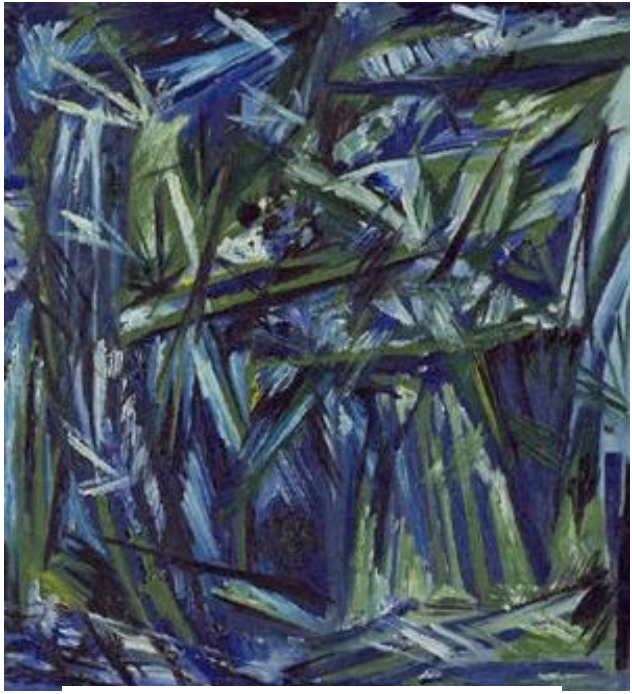

Floresta azul e verde (1911)

Natalia Gontcharova

Fonte: Internet.

Na visão de Meira,

Foi a construção raionista da pintura de Mikhail Larionov (1881-1964) que iniciou o processo de verdadeira independência com relação às referências estruturais conhecidas como a perspectiva, o desenho e a transição para a tela de dados da realidade. As manchas dinâmicas da cor tornaram-se a expressão essencial dessa pintura. Larionov se interessou pelo Futurismo, mas queria 
excluir dos horizontes de sua pintura os compromissos figurativos. (MEIRA, 2006, p. 88).

Tanto Larionov como Gontcharova, sua esposa, estavam engajados nas vanguardas da pintura russa. Já haviam participado do grupo "Valete de Ouros", fundado em 1909 como uma associação de artistas independentes com finalidade de realizar exposições da arte russa e européia. Dentre alguns artistas do grupo "Valete de Ouros" encontravam-se classificados (ainda) como neoprimitivista, Larionov e Gontcharova; segundo Humphreys (2000, p. 61), "o russo mais associado ao futurismo", Kasimir Maliêvitch (1878-1935); os cubistas de Paris Albert Gleizes (1881-1953) e Henri Le Fauconnier (1881-1946) e, ainda, os russos que trabalhavam em Munique, Vassili Kandinsky (1866-1944) e Alexei von Jawlensky (1864-1941). Esses dois últimos envolvidos no grupo de artistas residentes em Munique, denominado "O cavaleiro azul", importante grupo do expressionismo alemão.

Em 1911 deu-se a separação de alguns dos integrantes do "Valete de Ouros": Larionov, Gontcharova e Maliêvitch, que se desligaram sob o argumento de que a associação se deixara dominar pelo "orientalismo" provindo da Escola de Paris (CHILVERS, 2001, p. 542). Para Larionov, "o raionismo é uma síntese do cubismo, do futurismo e do orfismo" (CHILVERS, 2001, p. 436). Essa frase é parte integrante do Manifesto Raionista, atribuído ao pintor russo Mikhail Larionov, cuja publicação se deu em março de 1913 durante uma exposição chamada "Alvo", ocorrida em Moscou, organizada por Mikhail Larionov (1881-1964), Natália Gontcharova (18811962) e Kasimir Maliêvitch (1878-1935). Contudo, o movimento raionista teria se iniciado dois anos antes, porque algumas obras raionistas expostas naquela exposição de 1913, de Larionov e Gontcharova, foram produzidas em 1911, época em que produziam juntos obras neoprimitivas. Cabe elucidar que Maliêvitch, na exposição "Alvo”, apresentou telas futuristas (DEMPSEY, 2003, p. 102). Na produção raionista do casal Larionov e Gontcharova percebem-se os elementos de fusão do cubismo, do futurismo e do orfismo como fonte estética para o raionismo levar a cabo seu objetivo de representar apenas a luz refletida dos objetos. Há o uso de linhas oblíquas já empregadas pelos futuristas e cubistas, além das idéias do orfismo de Robert Delaunay (18851941), "nos quais os principais meios de expressão estão na composição de ritmos da cor" (DEMPSEY, 2003, p. 100).

A expressão "composição de ritmos" adequa-se ao momento urbano do século XX, composto de ritmos na indústria, na tecnologia, na ciência, nas artes, na percepção e no REVISTA DE ESTÉTICA E SEMIOTICA, BRASÍLIA, V. 1, N. 1 P. 91 -101, JUL./DEZ. 2011 
pensamento relativizado. Read (2000, p. 112) reforça a importância decisiva para o modernismo, dos movimentos como o orfismo de Delaunay, o raionismo do casal Larionov e Gontcharova, o Futurismo de Umberto Boccioni (1882-1916), Carlo Carrá (1881-1966) e Luigi Russolo (18851947). Ressalta-se que cada um tinha sua própria bandeira, seu próprio manifesto. O manifesto futurista (publicado no jornal francês "Le Figaro", em 1909) declarava que a verdade já não tinha como ser esgotada pela forma e pela cor, do modo como eram tratadas anteriormente, tendo em vista que no séc. XX tudo muda rapidamente, faz-se necessário se representar o dinamismo do movimento. Tal dinamismo encontra-se simbolizado nos "raios de luz" deflagrados em diversas angulações nas pinturas dos raionistas.

\section{O RAIONISMO À SOMBRA DA LITERATURA}

A partir da literatura a que tive acesso concluí que apenas o casal Mikhail Larionov e Natalia Gontcharova eram os integrantes do Raionismo, que já produziam antes pinturas neoprimitivistas e se tornaram, inclusive, no decorrer do tempo, marido e mulher. Em abril de 2009, o Centro Cultural do Banco do Brasil, de Brasília, recebeu a exposição chamada "Virada Russa". Na noite inaugural, em que se deu uma longa e produtiva palestra sobre a produção dos russos do início do século $\mathrm{XX}$, perguntei ao palestrante, que era russo (havia um tradutor), se o raionismo (que não foi mencionado na palestra e nem constou na exposição) seria um movimento artístico produzido apenas pelo casal Larionov e Gontcharova (era o que eu havia deduzido pela literatura, mas guardava minhas dúvidas). O russo palestrante afirmou que sim. É possível concluir, ainda, que o raionismo não durou além dos dois anos, devido sua escassa representatividade: apenas o casal de pintores. Malgrado o curto tempo de vida, o raionismo pode ser considerado como o primeiro movimento russo a apresentar uma pintura sem a tradição de uma narrativa, uma pintura não-figurativa na acepção do que o termo figurativo representou até aquele momento. A maneira do raionismo de representar a luz por meio de inúmeras linhas cruzadas entre si, predominantemente retilíneas, permite se concluir que buscavam representar artisticamente uma das propriedades físicas da luz - a reflexão.

Ao se representar os reflexos da luz, é possível se concluir que as linhas em suas múltiplas

diagonais "extrapolam" os limites da tela pintada, tendo em mente que não se pretendia REVISTA DE ESTÉTICA E SEMIOTICA, BRASÍLIA, V. 1, N. 1 P. 91 -101, JUL./DEZ. 2011 
interromper o fluxo luminoso representado pictoricamente. Cabe ao observador imaginar os prolongamentos dos raios de luz para além das fronteiras físicas da tela.

A "vanguarda ${ }^{2}$ russa" (expressão presente na literatura) deixava claro seu distanciamento com a noção de "realidade" ou "naturalismo" em nome de uma desejável ruptura com a tradição figurativa. Na pauta de interesses dos pintores modernistas europeus da primeira década do séc. XX estava uma busca por novos objetos visuais, novas formas (aparências), onde as mentes artísticas ousassem visualizar o "mundo novo" com novas dimensões conceituais. Mas, sobretudo, era preciso coragem desses mesmos artistas para manifestar seus interesses, em certa medida ininteligíveis ao público tradicional (prefiro dizer, pessoas alfabetizadas com outro vocabulário, outro idioma estético), até que a pintura moderna do mundo ocidental se revelasse ao intelecto, aos olhos e à imaginação de cada observador, como uma experiência fenomenológica.

O raionismo é uma palavra, é um termo criado por Gontcharova em 1912 (e publicado no manifesto em 1913), devido ao interesse de Larionov em ciência (BOWLT, 1976, p. 92). As obras de Larionov e Gontcharova apresentadas nesse trabalho podem compor, ao lado das obras de Kandinsky e Maliêvitch, o marco histórico da pintura não-figurativa na Rússia. Lamentavelmente as obras que trago como exemplo não constam em nenhum dos 30 livros de História da Arte, pesquisados durante esse estudo. Foi necessário recorrer à Internet. Por outro lado, as demais obras trazidas como exemplo nesse trabalho, produzidas nos séculos XII, XIV, XVII e XIX, constam nas páginas em mais de uma das várias literaturas sobre História da Arte publicadas no Brasil. Assim, à guisa de reflexão, foi possível perceber que o raionismo não recebeu suficiente atenção do mercado editorial especializado na literatura em Teoria e História da Arte, traduzida em língua portuguesa e nas obras literárias francesas a que tive acesso. A ausência de um determinado movimento artístico na literatura especializada em Teoria e História da Arte pode ser uma fonte de questionamento sobre a natureza das categorias de conceitos e critérios que editores e historiadores de arte estariam adotando para elencar os movimentos artísticos que apresentam ou discutem nas obras literárias que resolvem produzir.

A seguir, apresento uma lista de 19 livros que não tratam do raionismo, nem mencionam os nomes de Mikhail Larionov e Natalia Gontcharova: 1) D'AGOSTINO Carmelo. Arte moderna,

\footnotetext{
${ }^{2}$ Perguntei ao russo que dava a palestra na exposição "Virada Russa" se os artistas teriam adotado esse termo para fazer referência a si próprios e suas obras. Não!, respondeu o palestrante russo. Nenhum deles deixou escrito que se consideravam "vanguarda" e, por isso mesmo, o nome da exposição é "Virada Russa".
} 
uma monstruosidade... São Paulo: Gráfica Revista dos tribunais, 1968. 232 p. ilust.; 2) FAURE, Élie. Histoire de l'art: l'esprit des formes I. Paris: Éditions Gallimard, 1991. 456 p. ilust.; 3) FAURE, Élie. Histoire de l'art: l'esprit des formes II. Paris: Éditions Gallimard, 1991. 498 p. ilust.; 4) FERRY, Luc. Le sens du beau: aux origines de la culture contemporaine. Italie: Éditions Cercle d'Art, 1998. 237 p. ilust.; 5) FRANCASTEL, Pierre. Art et technique aux XIX et XX ${ }^{e}$ siècles. Paris: Éditions Gallimard, 2000. 302 p. ilust.; 6) FRY, Roger. Visão e forma. Tradução de Cláudio Marcondes. São Paulo: Cosac e Naif, 2002. 360 p. ilust.; 7) GOMBRICH, E. H. Arte e ilusão. Tradução de Raul de Sá Barb. São Paulo: WMF Martins Fontes, 2007.386 p. ilust.; 8) GOMBRICH, E. H. A história da arte. Tradução de Álvaro Cabral. Rio de Janeiro: Editora LTC, 1999. 680 p. ilust.; 9) HARRISON, Charles. Modernismo. Tradução de João Moura. São Paulo: Cosac e Naif Edições, 2000. 80 p. ilust.; 10) HAUSER. Arnold. História social da arte e da literatura. Tradução de Álvaro Cabral. São Paulo: Martins Fontes, 1998. 1032 p.; 11) JANSON, H. W. História geral da arte: o mundo moderno. São Paulo: Martins Fontes, 2001. 291 p. ilust.; 12) KIEFFER, Anne. L'indispensable de la culture générale: la peinture - des origines à nos jours. 2. ed. Paris: Éditions Studyrama, 2004. 185 p.; 13) KRAUBER, Anna-Carolina. História da pintura: do renascimento aos nossos dias. Tradução de Ruth Correia e Miriam Tomás-Medeiros. Colônia: Könemann, 2001.128 p. ilust.; 14) KEMP, Martin. História da Arte no Ocidente. Lisboa - Portugal: Editorial Verbo, 2006. 564 p., ilust.; 15) LITTLE, Stephen. Ismos: entender a arte. Lisboa: Lisma, 2006. 160 p. ilust.; 16) LOON, Hendrik Willem Van. As Artes. Tradução de Marina Guaspari. Porto Alegre: Livraria do Globo, 1939. 633 p.; 17) STRICKLAND, Carol. Arte comentada: da pré-história ao pós-moderno. Tradução de Ângela Lobo de Andrade. 9. ed. Rio de Janeiro: Ediouro, 2003. 198 p. ilust.; 18) WEBER, Patrick. Histoire de l'art et des styles: architecture, peinture, sculpture, de l'Antiquité à nos jours. Paris: Librio, 2005. 95 p. ilust.; 19) WOLLHEIM, Richard. A pintura como arte. Tradução de Vera Pereira. São Paulo: Cosac e Naif, 2002. 384 p. ilust.

\section{REFERÊNCIAS}

ARGAN, Giulio Carlo. Arte moderna. Tradução de Denise Bottmann e Federico Carotti. São Paulo: Companhia das Letras, 1992.709 p. ilust. 
BAXANDALL, Michael. Padrões de intenção: a explicação histórica dos quadros. Tradução de Vera Maria Pereira. São Paulo: Companhia das letras, 2006. 213 p. ilust.

BOWLT, John E. The documents of 20th century art. Russian art of the Avant-Garde: theory and criticism: 1902-1934. New York: the Viking Press Inc., 1976.

CHILVERS, Ian. Dicionário Oxford de arte. Tradução de Marcelo Brandão Copolla. - 2. ed. São Paulo: Martins Fontes, 2001. 584 p.

DEMPSEY, Amy. Estilos, escolas e movimentos. Tradução de Carlos Eugênio Marcondes de Moura. São Paulo: Cosac Naify, 2003. 304 p. ilust.

GOMBRICH, E. H. A história da arte. Tradução de Álvaro Cabral. Rio de Janeiro: Editora LTC, 1999. 680 p. ilust.

HUMPHREYS, Richard. Futurismo. Tradução de Luiz Antônio Araújo. São Paulo: Cosac e Naif Edições, 2000. 80 p. ilust.

KEMP, Martin. História da Arte no Ocidente. Lisboa - Portugal: Editorial Verbo, 2006. 564 p., ilust.

MEIRA, Silvia Miranda. A imagem moderna - um olhar. Belo Horizonte: C/Arte, 2006. 144 p. ilust.

PERLOFF, Marjorie. O momento futurista. Tradução de Sebastião Uchoa Leite. São Paulo: Editora da Universidade de São Paulo, 1993. 404 p. ilust.

READ, Herbert. Uma história da pintura moderna. Tradução de ivone Castilho Benedetti. São Paulo, Martins Fontes, 2000. 409 p. ilust.

Imagens raionistas de Mikhail Larionov. Disponível em http://oseculoprodigioso.blogspot.com/2 007/09/larionov-mikhail-cubismo.html, acessado em 10 de junho de 2008, às 14h27min.

Imagens raionistas de Natalia Gontcharova. Disponível em http://images.google.com.br/imgres?i mgurl=http://www.moma.org/collection/provenance/items/images/1012.83.jpg\&imgrefurl=http:// www.moma.org/collection/provenance/items/1012.83.html, acessado em 10 de junho de 2008, às $15 \mathrm{~h} 11 \mathrm{~min}$. 